\title{
Use of topical steroids on the face among university students in Saudi Arabia.
}

\author{
Dhiyaa Majed", Mahdi Alnujaidi', Nawaf Almohammadi', Amal A Kokandi ${ }^{2}$ \\ ${ }^{1}$ Faculty of Medicine, King Abdulaziz University, Rabigh, Jeddah, Saudi Arabia \\ ${ }^{2}$ Department of Dermatology, Faculty of Medicine, King Abdulaziz University, Saudi Arabia
}

\begin{abstract}
Background: Topical corticosteroids are widely used to treat dermatological problems. The aim of this study is to assess the scale of topical steroid usage on the face among the university students.

Methods: An online questionnaire has been sent by e-mail to all students of King Abdulaziz University (Jeddah, Saudi Arabia). It included questions about the use of topical steroids on the face for the last $5 \mathrm{y}$. Different photos of commonly used topical steroids including combination formulas were shown and asked if they have been used.

Results: 1626 students responded. Only 56 responded as they have used topical steroids on the face in the previous $5 \mathrm{y}$. At least 189 had used one of the presented photos (which contained steroids) and 637 said that they did not know that they contained steroids. Sources of prescription included dermatologists, other doctors, pharmacists, friends and relatives, beauticians or saloon staff and others. Different recognized side effects were reported.

Conclusion: Considerable number of university students use topical steroids on the face without knowing its nature. Additionally, Topical steroids are being prescribed and advised by non-medical personnel. Public awareness actions can be implemented to warn against the use of topical steroids without proper medical consultation.
\end{abstract}

Keywords: Face, Side effects, Topical corticosteroids.

\section{Introduction}

Topical corticosteroids are widely used to treat dermatological problems. They are used to ameliorate inflammation and for other purposes. They come in different formulations and different potencies. Mild formulations are usually used for children and for sensitive areas. Although topical steroids are used for many skin diseases, they are contraindicated in some diseases and might cause side effects if used inappropriately. If they are used for prolonged periods of times they can cause side effects [1]. Topical steroids misuse can cause numerous side effects. In one study, tinea incognito and acne were reported mostly [2]. In another study (involving 100 patients) investigating the side effects of side effects of steroid use on the face, pruritus, acne from eruption, erythema, photo sensitivity, steroid dependency and telangiectasia were reported [3].

One of the common topical side effects of topical steroids is whitening of the skin. Unfortunately, this side effect is being used by some people to lighten skin pigmentations or to lighten their natural color or to lighten hyper-pigmentations [4-6]. This phenomenon was also found to be used in Saudi for the same purpose [7]. Steroids are added illegally as well to whitening products to lighten skin or to enhance the lightening effect of other ingredients [8].
The regulation on the sale of topical steroids differs among countries. In Saudi currently, topical steroids in different strengths can be purchased without medical prescription from pharmacies. Additionally, they can be purchased through different routes such as herbal shops or online. Some steroid containing creams and ointments are particularly popular in our country. In clinical practice some of these are very well known to be used by public without prescription or advocated by nonmedical personnel. Some of these formulations are combination formulas containing antibacterial or anti-fungals. Potent steroids are very commonly used as well as combination formulas.

The aim of this study is to assess the scale of topical steroid usage on the face among the university students.

\section{Methods}

An online questionnaire has been sent through e mail to all students of King Abdulaziz University (Jeddah, Saudi Arabia) through a questionnaire program (survey monkey). The questionnaire has been sent through the deanship of higher education following a standard procedure of ethical approval from the biomedical research committee and an approval from the deanship to around 30,000 students with registered e-mails. 
The questionnaire included demographic questions about the student (age, gender and faculty of student); followed by a question asking about if they have used any topical steroid on the face for the previous 5 y. 4 pictures including the most commonly used topical steroids (including combination formulas) then shown and asked if they have used any one of these topicals on the face for the previous $5 \mathrm{y}$. The photos were of commonly used steroid formulas. The first picture contained photos of mild topical steroids (alfacort cream, cortiderm cream, resolve plus, fucidin $\mathrm{H}$ cream and pimafucort cream). Second picture contained photos of potent and superpotent steroids (betasone cream, gamavate cream, dermovate cream and gel, metaz cream, betaderm cream, betnovate cream and betamet cream). Third picture contained photos of other group of potent steroids (elica cream, locoid lipocream, locoid cream, elocom cream). Finaly, fourth picture contained photos of combination formulas with potent steroids (kenacomb cream, elica-M cream, fucicort cream, betazol cream, panderm cream, fucibact $\mathrm{B}$ cream and salibet ointment).

If they have used any one of them they were asked if they knew that it contained steroids and how long did they use it for. If they have used any what was the reason, who prescribed it, if satisfied about the result and if suffered from any side effects.

The study protocol was approved by the unit of biomedical ethics research committee at King Abdulaziz university Hospital, Jeddah, Saudi Arabia (Reference No: 164-16).

All data were exported from the questionnaire program to Excel 2013 for the statistical calculations.

\section{Results}

In total 1626 students have responded to the questionnaire. Most of the respondents were at the age group of $20 \mathrm{y}$ or less $(50.74 \%)$, followed by age group of $21-25$ y $(28.17 \%)$.

Table 1. Responses to the use of topical corticosteroids shown in the photos on the face.

\begin{tabular}{|c|c|c|c|c|c|}
\hline $\begin{array}{l}\text { Type of steroids } \\
\text { in the photos }\end{array}$ & Yes & No & $\begin{array}{l}\text { Not } \\
\text { sure }\end{array}$ & $\begin{array}{l}\text { Number of } \\
\text { responses }\end{array}$ & $\begin{array}{l}\text { Skipped the } \\
\text { question }\end{array}$ \\
\hline \multirow[b]{2}{*}{ Mild steroids } & 476 & 960 & 150 & \multirow[b]{2}{*}{1586} & \multirow[b]{2}{*}{40} \\
\hline & -0.3001 & $\begin{array}{l}-0.605 \\
3\end{array}$ & $\begin{array}{l}-0.094 \\
6\end{array}$ & & \\
\hline \multirow[b]{2}{*}{ Potent steroids } & 189 & 1227 & 127 & \multirow[b]{2}{*}{1543} & \multirow[b]{2}{*}{83} \\
\hline & -0.1225 & $\begin{array}{l}-0.795 \\
2\end{array}$ & $\begin{array}{l}-0.082 \\
3\end{array}$ & & \\
\hline \multirow[b]{2}{*}{ Potent steroids } & 256 & 1165 & 90 & \multirow[b]{2}{*}{1511} & \multirow[b]{2}{*}{115} \\
\hline & -0.1694 & -0.771 & $\begin{array}{l}-0.059 \\
6\end{array}$ & & \\
\hline \multirow{2}{*}{$\begin{array}{l}\text { Combination } \\
\text { formulas }\end{array}$} & 538 & 835 & 111 & \multirow[b]{2}{*}{1484} & \multirow[b]{2}{*}{142} \\
\hline & -0.3625 & $\begin{array}{l}-0.562 \\
7\end{array}$ & $\begin{array}{l}-0.074 \\
8\end{array}$ & & \\
\hline
\end{tabular}

Females were $68.76 \%$ and $31.24 \%$ were male. Most of the respondents were in their first preparatory year of study. Only
$3.44 \%$ (56 respondents) replied yes to the question of using topical steroid preparation on their face for the last $5 \mathrm{y}$ period, $64.02 \%$ (1041) replied no, 26.69\% (434) were not sure and $5.84 \%$ (95) mentioned the cream they have used. The creams mentioned were mostly topical steroids, but some of them were unknown or not steroids at all (like Vaseline).

On questioning about whether they have used any one of the preparations presented in the photos, data is presented in Table 1.

On questioning if weather they knew that these preparations contained steroids, $189(22.88 \%)$ replied yes and $637(77.12 \%)$ said no they did not know (total responses was 826 and 800 skipped the question).

The reason for using the preparation was mostly to treat acne by $262(32.19 \%)$, and to treat other facial problems by 237 $(29.12 \%)$, for general purpose as after shaving or hair removal by $191(23.46 \%)$, for facial redness by $116(14.25 \%)$, for whitening by $52(6.39 \%)$ and other reasons by $234(29.85 \%)$. The source of advice of the topical is presented in Figure 1. Dermatologists, friends and relatives followed by pharmacist were the most common sources.

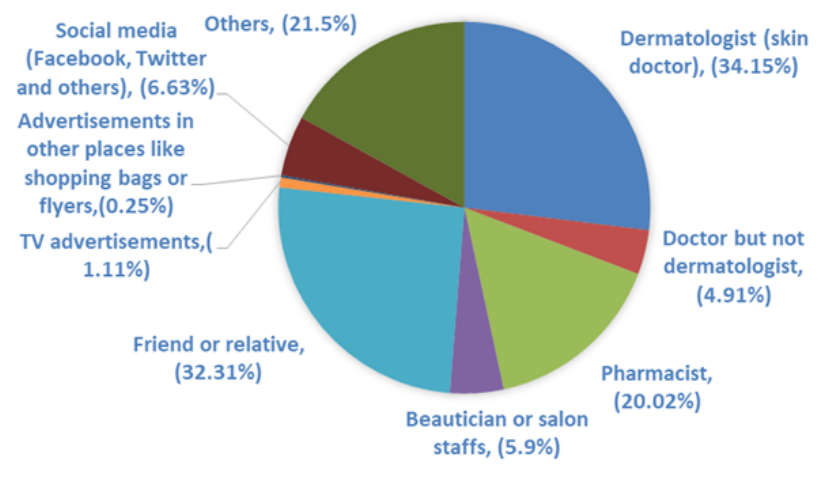

Figure 1. Source of advice for the use of topical steroids.

Out of 819 respondents who answered this question, 376 $(45.91 \%)$ were satisfied with the results of the topical, 132 $(16.12 \%)$ were not satisfied and $207(25.27 \%)$ were not sure. Side effects were experienced by $62(7.60 \%)$, and were not experienced by $705(86.40 \%)$. The side effects mentioned were: change in skin colour (darkening or whitening), dryness and peeling, sensitive skin, recurrence of problem after stopping the topical, redness, itchiness, appearance of small vessels and increase of acne pimples.

\section{Discussion}

Topical steroids are important medications in treating skin diseases, but their misuse can cause skin dependence or side effects. Their use should be under dermatologist advice especially potent formulations. Public use of topical steroids without medical supervision or for reasons not recommended medically in other communities have been studied and published. To our knowledge this has not been explored in our area. 
In this study, we aimed to assess the scale of topical steroid usage on the face among the university students though e mail invitation to an online questionnaire. We have chosen to ask about the face because it represents an especially sensitive area to the effect of topical steroids and use of topicals to this area could be memorized more as we thought. It showed that, considerable number of students used topical steroids on the face. Moreover, some used some preparations containing steroids without realizing the nature of them, including very potent ones.

The reasons to use topical steroids were similar to reasons described in other communities. In Western Nepal, patients using topical steroids on the face were studied. The most common reason for using steroids were as whitening agent and to treat acne. Most patients were unaware of side effects of topical steroids [9]. In another study in Pakistan, 200 patients with steroidal dermatitis resembling rosacea were studied. $50 \%$ of those patients used topical steroids combined with whitening creams and 33\% used steroids only. The topical steroids were prescribed by friends, relatives and peers mainly followed by physicians or general practitioners, beauticians, self, chemists, and others. Similar to previous study patients were unaware of side effects [10].

Many studies have been published in Indian populations for the use and misuse of topical steroids. A small study (50 patients) looking at de-pigmenting agents users found that more than $70 \%$ were using topical steroids for this purpose. $80 \%$ of these patients obtained these agents by over the counter sale, while only $4 \%$ had them after dermatological consultation [11]. In another study, topical steroid on the face was evaluated in 200 patients attending the dermatology outpatient clinic showed that all patients were unaware about the side effects of the topical steroids despite having the side effects [12]. In this study, the reason for using the steroids mostly was to treat acne, followed by whitening. The most common side effect was acne and steroid dependence. In a larger study of 1000 adults attending dermatology outpatient setting, 61.2\% have used one of the topical steroids. The most common purposes of use were acne and pigmentation. Strikingly, about half of them experienced some form of side effects. These topical were mainly prescribed by general physicians $(49.5 \%)$, followed by suggestions from friends $(31-32 \%)$, or given by other family members $(6.3 \%)$ [13]. In an earlier study in India with a larger sample and multi-center study, a total of 2926 patients with facial dermatoses were screened, of which around $15 \%$ were using topical steroids. They were used as a fairness/general purpose cream or aftershave or for acne treatment. Of note, nearly $60 \%$ of those were recommended by non-physicians. Additionally, in the physician prescription group $44 \%$ were prescribed by non-dermatologists [14]. In another study looking at topicals used among facial dermatosis patients revealed that most of them used topical steroids either alone or in combination with other medications. More than $40 \%$ bought topical steroids over the counter on their own without dermatologist consultation. They were recommended by beautician (beauty parlours), friends, family members, or neighbours and a non-dermatologist practitioner. In only $10 \%$ it was recommended or prescribed by dermatologist [15]. In a large study collecting data from patients presenting with one of the topical steroids side effects, the main reason for using the topical was to lighten skin color and the many side effect encountered was acne and telangectasia [16].

In this study only few students admitted using topical steroids on the face for the last 5 y (56 students). But on questioning about the usage of any of the presented creams in the picture (which included commonly used topical steroids) on the face for the last $5 \mathrm{y}$, up to 538 students have done so. This indicates that they did not know the nature of these creams. Moreover, up to 256 have used potent steroids on the face. In 278 cases these were prescribed by dermatologists. It is unknown whether; it has been explained in these cases keeping in mind the discrepancy in number of knowledgeable students about their used creams. Other sources of advice included friends or relatives mostly, followed by pharmacists, social media (Facebook, Twitter and others, beauticians or salon staffs then other specialty doctors.

The reported side effects by students in this questionnaire are well recognized side effects of topical steroids. These included changes in skin color (darkening or whitening), dryness and peeling, sensitive skin, recurrence of problem after stopping the topical, redness, itchiness, and appearance of small vessels and increase of acne pimples.

In conclusion, considerable number of university students use topical steroids on the face without knowing its nature. Additionally, topical steroids are being prescribed and advised by pharmacists, beauticians, friends and relatives or social media. Recognized local side effects are reported in this study. More control on the dispensing of topical steroids is warranted and public awareness actions can be implemented to warn against the use of topical steroids without proper medical consultation.

\section{Conflict of Interest}

The authors have no conflict of interests.

\section{Disclosure}

The authors did not receive any type of commercial support either in forms of compensation or financial for this study.

\section{Ethical Approval}

Obtained.

\section{References}

1. Hengge UR, Ruzicka T, Schwartz RA, Cork MJ. Adverse effects of topical glucocorticosteroids. J Am Acad Dermatol 2006; 54: 1-5.

2. Meena S, Gupta LK, Khare AK, Balai M, Mittal A, Mehta S, Bhatri G. Topical corticosteroids abuse: A clinical study of cutaneous adverse effects. Indian J Dermatol 2017; 62: 675 . 
3. Manchanda K, Mohanty S, Rohatgi PC. Misuse of topical corticosteroids over face: A clinical study. Indian Dermatol Online J 2017; 8: 186-191.

4. Sharma R, Abrol S, Wani M. Misuse of topical corticosteroids on facial skin. A study of 200 patients. J Dermatol Case Rep 2017; 11: 5-8.

5. Sendrasoa FA, Ranaivo IM, Andrianarison M, Raharolahy O, Razanakoto NH, Ramarozatovo LS, Rapelanoro Rabenja F. Misuse of topical corticosteroids for cosmetic purpose in Antananarivo, Madagascar. Biomed Res Int 2017; 2017: 9637083.

6. Nnaruka E, Okoye O. Topical steroid abuse: Its use as a depigmenting agent. J Natl Med Assoc 2006; 98: 934-939.

7. Alanzi ME, Alghamdi RA, Alsharif OM, Alghamdi KS, El Sayed SM. Health knowledge, cosmetic interests, attitude, and the need for health education regarding the use of topical bleaching agents among women in West Saudi Arabia: A cross-sectional study. J Cosmet Sci 2018; 69: 101-120.

8. Maneli MH, Wiesner L, Tinguely C, Davids LM, Spengane Z, Smith P, van Wyk JC, Jardine A, Khumalo NP. Combinations of potent topical steroids, mercury and hydroquinone are common in internationally manufactured skin-lightening products: a spectroscopic study. Clin Exp Dermatol 2016; 41: 196-201.

9. Kumar A, Neupane S, Shrestha PR, Pun J, Thapa P, Manandhar M, Sathian B. Pattern and predictors of topical corticosteroid abuse on face: A study from Western Nepal. Res J Pharm Biol Chem Sci 2015; 6: 1154-1159.

10. Chohan SN, Suhail M, Salman S, Bajwa UM, Saeed M, Kausar S, Suhail T. Facial abuse of topical steroids and fairness creams: a clinical study of 200 patients. J Pak Assoc Dermatol 2014; 24: 204-211.
11. Sinha A, Kar S, Yadav N, Madke B. Prevalence of topical steroid misuse among rural masses. Indian $\mathrm{J}$ Dermatol 2016; 61: 119 .

12. Hariharasubramony AHC, Vinod S, Yadalla H, Nithya R, Babu AR. Topical corticosteroid abuse on the face: a prospective study on outpatients of dermatology. Our Dermatol Online 2014; 5: 5-8.

13. Nagesh TS, Akhilesh A. Topical steroid awareness and abuse: a prospective study among dermatology outpatients. Indian J Dermatol 2016; 61: 618-621.

14. Saraswat A, Lahiri K, Chatterjee M, Barua S, Coondoo A, Mittal A, Panda S, Rajagopalan M, Sharma R, Abraham A, Verma SB, Srinivas CR. Topical corticosteroid abuse on the face: a prospective, multicenter study of dermatology outpatients. Indian J Dermatol Venereol Leprol 2011; 77: 160-166.

15. Jha AK, Sinha R, Prasad S. Misuse of topical corticosteroids on the face: A cross-sectional study among dermatology outpatients. Indian Dermatol Online J 2016; 7: 259-263.

16. Dey VK. Misuse of topical corticosteroids: A clinical study of adverse effects. Indian Dermatol Online J 2014; 5: 436-440.

\section{*Correspondence to}

Amal A Kokandi

Department of Dermatology

Faculty of Medicine

King Abdulaziz University

Saudi Arabia 